\title{
DO EXÍlIO AO ARQUIVO: RASTROS DE HILDE DOMIN ${ }^{1}$
}

\author{
Fernando Miranda ${ }^{2}$
}

Resumo: $\mathrm{O}$ objetivo deste trabalho é apresentar alguns resultados da pesquisa no espólio (Nachlass) da poeta alemã Hilde Domin, que se encontra no Arquivo Literário Alemão (Deutsches Literaturarchiv), em Marbach am Neckar. Com isso, pretendo oferecer elementos para o debate em torno da pesquisa em arquivo e quais contribuições esses debates podem proporcionar aos estudos de literatura, além de trazer novos resultados para as pesquisas da poesia de pós-guerra (Nachkriegslyrik).

Palavras-chave: Hilde Domin; arquivo; poesia; pós-guerra; antropologia literária

Abstract: This paper presentes some results of the research into the estate (Nachlass) of the German poet Hilde Domin, stored at the German Literature Archive (Deutsches Literaturarchiv) in Marbach am Neckar. By presenting those results, I offer elements to the debate about archival research, presente contributions of these debates to Literary Studies, and also bring new results for the researches into post-war poetry (Nachkriegslyrik).

Key words: Hilde Domin; archive; poetry; pot-war; literary anthropology

\section{Primeiras considerações}

Edições críticas, contendo inúmeras notas de rodapé, anexos informando as alterações que o poeta fez nos versos, antes ou mesmo depois da publicação de um poema, inclusão de comentários privados que de alguma maneira se associam ao texto literário apresentado; a publicação de correspondências, às vezes contendo somente as cartas enviadas pelo autor, às vezes apresentando o diálogo epistolar que se construiu por anos, por décadas. Esses dois tipos de material podem ser complementares, contribuindo para um maior - ou diferente -

1 A pesquisa para o presente trabalho foi financiada pelo Deutsches Literaturarchiv, com uma bolsa Hilde Domin para scholars latino-americanos.

${ }^{2}$ Doutorando UFF - fernandogalo@hotmail.com 
entendimento da obra de um autor, de uma época, de um movimento literário, ou podem, sobretudo o segundo, cair meramente no anedótico, satisfazendo apenas a curiosidade. Como se estabelece o limite entre um trabalho de arquivo eficiente e um simples passatempo para curiosos?

O trabalho em arquivo é um trabalho com a memória cultural. No entanto, ao lidar com documentos pessoais, como cartas trocadas entre familiares, diários, etc., nos deparamos também com vestígios de memória comunicativa $^{3}$, a não ser que acreditemos que um autor, ao enviar uma carta a um parente, por exemplo, estivesse encenando uma transmissão num arco temporal maior que o da memória comunicativa, já pressupondo que gerações muito posteriores teriam acesso ao material ${ }^{4}$.

Para lidar com a memória, é preciso encontrar a teoria, evitando, assim, perder-se num emaranhado de informações. Se isso não é novidade para o historiador ou mesmo para os antigos filólogos, como nós, estudiosos de literatura habituados a uma hermenêutica centrada no texto literário, podemos nos comportar? Em primeiro lugar, sabemos que a teoria precisa deixar o espaço para a surpresa, para o aparecimento daquilo que não se espera. Em termos mais concretos: é preciso aceitar a contingência e estar atento ao que uma carta aparentemente desimportante pode trazer à luz. Se estamos acostumados a partir do resultado final - um poema, um conto, um romance - e dele elaborarmos uma série de leituras, o confronto com o arquivo nos coloca diante de um duplo passado: o passado em si, aquele em relação ao nosso presente, e o passado passado ${ }^{5}$, aquele em relação ao tempo da obra concluída.

${ }^{3}$ Uso os termos apropriando-me de kulturelles Gedächtnis (memória cultural) e kommunikatives Gedächtnis (memória comunicativa) de Jan Assmann. O primeiro se refere a um tempo amplo, acessivel pelo trabalho arqueológico, histórico, etc., enquanto o segundo se restringe a três gerações e à sua transmissão oral. Cf. ASSMANN, Jan. Das kulturelle Gedächtinis - Schrift, Erinnerung und politische Identität in frühen Hochkulturen. München: C.H. Beck, 2013

${ }^{4}$ No Arquivo Literário Alemão é possível encontrar Vorlass (um "espólio" em vida) de alguns autores, como Peter Handke e Hans Ulrich Gumbrecht. Esses materiais só podem ser consultados com autorização do próprio autor. Para o argumento, aqui, interessa perceber que os autores que possuem Vorlass cuidados pelo Arquivo têm consciência que seu material será preservado e poderá ser acessado no futuro.

${ }^{5}$ Jogo com o sintagma de Reinhart Koselleck, "futuro passado", em que a pesquisa histórica pode observar as visões de futuro num determinado ponto histórico passado e averiguar o que se cumpriu ou não e como se cumpriu dentro daqueles 
Poderíamos afirmar que uma obra nunca se conclui, pois a atribuição de sentido a ela sempre a renova. Porém, atento para o fato de que a sua materialidade, a sua presença, já está devidamente formada. No trabalho em arquivo, podemos ir ao passado não do sentido, mas ao da própria presença. $^{6}$

Ter essa consciência ainda nos deixa outras questões. Por exemplo: após irmos ao passado passado, o que trazemos dele? O que esse passado passado pode iluminar na obra literária? Ele pode dizer apenas algo sobre determinada obra ou pode ser uma contribuição mais ampla, trazendo ricos elementos para as pesquisas na história das ideias? Ao observar o arquivo de Hilde Domin, abordado aqui, algumas respostas podem começar a ser formuladas. Não fica demais lembrar que uma teoria e um método de trabalho que incluem o arquivo em seu corpo não devem excluir abordagens imanentistas. Um trânsito entre as duas formas de trabalho pode proporcionar resultados mais ricos.

\section{Percurso: ao exílio}

Nascida a 27 de julho de 1909, Hilde Löwenstein, posteriormente Hilde Palm, pelo casamento com Erwin Walter Palm, e também Hilde Domin, pseudônimo da poeta, possui um trânsito curioso e atípico no que diz respeito aos autores exilados e da literatura de pós guerra? Realizando um período de estudos na Itália, junto com seu então namorado Erwin, Hilde é surpreendida pela ascensão de Hitler ao poder, em 1933. Por isso, o casal decide permanecer no país até que em 1936 a situação de torna mais desconfortável, com o pacto Roma-Berlim, que passou a criar um ambiente negativo aos judeus também na Itália. Em 1939, quando a permanência se torna insustentável, partem para a

prognósticos. Cf. KOSELLECK, Reinhart. Futuro passado - contribuição à semântica dos tempos históricos. trad. Wilma Patrícia Maas e Carlos Almeida Pereira. Rio de Janeiro: Contraponto, PUC-Rio, 2006

${ }^{6}$ Para a diferenciação entre sentido e presença, cf. GUMBRECHT, Hans Ulrich. Produção de presença - o que o sentido não consegue transmitir. trad. Ana Isabel Soares. Rio de Janeiro: Contraponto, PUC-Rio, 2010

7 Como ressaltam Harald Vogel e Michael Gans, Domin não vivenciou fisicamente a Alemanha nazista, pois já se encontrava no exterior quando Hitler chegou ao poder. VOGEL, Harald e GANS, Rose Ausländer - Hilde Domin Gedichtinterpretationen. Baltmannsweiler: Schneider Verlag, 1998 
Inglaterra, onde os pais de Hilde já se encontravam exilados. Não demorará até que os alemães sejam declarados enemy aliens pelos ingleses, e logo em 1940 o casal deixa a ilha, rumo à República Dominicana. Em entrevista de 1994 (apud HERWEG, 2011, p. 43), Hilde Domin esclarece por que o país da América Central foi seu destino:

No consulado guatemalteco me diziam, por exemplo, que era bem-vinda a imigração de engenheiros, mecânicos etc. Não se interessavam por pessoas das ciências humanas. Para o Chile, Brasil, Argentina ou mesmo Canadá se podia ir, desde que se dispusesse de cerca de mil dólares, o que não tínhamos. A República Dominicana não colocava nenhuma exigência desse tipo. ${ }^{8}$

O motivo da acolhida no país centroamericano não era uma bondade humanística, mas parte do projeto do ditador Rafael Trujillo para desenvolver o país. Um grande número de imigrantes alemães, refugiados judeus - estima-se que cerca de 100 mil - foi recebido. Erwin Palm logo teria uma vaga como professor de arqueologia na Universidad de Santo Domingo, enquanto Domin permaneceria como uma secretaria não oficial, traduzindo os trabalhos dele, fotografando seus estudos e, durante um relativo curto período, lecionando alemão na universidade.

Somente em 1954 o casal retornará a Alemanha, numa fase ainda instável para os dois, com estações em Frankfurt e Espanha, até que Erwin se estabelece como professor na Universität Heidelberg e os dois podem, finalmente, construir uma moradia. Permanecerão nessa cidade até a morte - dele, em 1988, e dela, em 2006 -, onde hoje se encontram enterrados, em túmulos lado a lado, no Bergfriedhof.

$\mathrm{O}$ aspecto biográfico nunca ficou de fora da encenação de Hilde Domin enquanto poeta. Um volume de textos autobiográficos foi publicado em 1974, sob o título Von der Natur nicht vorgesehen (Não

\footnotetext{
${ }^{8}$ Salvo quando indicado, todas as traduções são minhas e feitas exclusivamente para facilitar a leitura deste trabalho. "Im Konsulat von Guatemala sagte man mir z.B. die Einwanderung von Ingenieuren, Technickern usw. sei erwünscht, Geisteswissenschaftler seien nicht gefragt. Nach Chile, Brasilien oder Argentinien, oder auch nach Kanada, konnte man gehen, wenn man soundsoviel tausend Dollar hatte, aber die hatten wir nicht. Die Dominikanische Republik stellte keine derartigen Anforderung".
} 
prevista pela natureza), ampliado em 2005 como Gesammelte autobiographische Schriften - fast ein Lebenslauf (Escritos autobiográficos reunidos - quase um currículo). $O$ que interessava, nessa maneira de mostrar a vida de uma poeta, era expor e refletir sobre a condição humana. Apesar de a escrita servir como apoio nos frágeis momentos da existência, como será visto adiante, no momento em que se assume a forma poética, o autor passa a uma responsabilidade, a uma ética, inerente a sua função: "o poeta nos oferece a pausa" (DOMIN, 2005a, p. 26), pois a arte e o amor "modificam nossa percepção temporal" (ibidem, p. 26). Há uma grande distância entre o simples relato de um tortuoso percurso em exílio e a sua transformação - poderíamos dizer metamorfose - em discurso poético. Se é da experiência que se parte, não é nela que se permanece encerrado. Quando Domin afirma que "[a] poesia nos convida ao encontro mais simples e difícil de todos, o encontro conosco mesmo" 10 (ibidem, p. 26), não propõe uma autorreferência, isto é, não é o poeta, ao escrever o poema, que se encontra consigo, mas o leitor, ao encontrar o poema - e o poeta -, que pode, pela pausa, pela respiração, realizar uma espécie de epoché e, dessa maneira, encontrar novos sentidos - das coisas, da vida, do mundo, de si. Nesse caso, se a poesia não é capaz de transformar a realidade - uma guerra será uma guerra, independente da ação do poema -, ela é capaz de se inserir em uma realidade e manter com ela uma relação tensiva, alterando a estrutura ontológica na qual está imerso o sujeito.

No tocante à escrita como apoio nos momentos frágeis da existência, a uma escrita de fato como salvação, é possível identificar dois momentos em Domin: o primeiro, publicamente, enquanto personagem poética; o segundo momento permanece ainda hoje inédito e só é possível de ser conhecido pelas correspondências com o editor Rudolf Hirsch.

O momento público se refere ao seu nascimento poético, em 1951, na República Dominicana. Apesar de ser apresentado ao leitor através do texto autobiográfico, também alguns aspectos relevantes dessa transformação - metamorfose - só virão a conhecimento postumamente, sobretudo com a publicação das correspondências entre ela e Erwin Palm, organizadas por Jan Bürger e Frank Druffner, em 2009. Por ora, detenho-

9 "Der Lyriker bietet uns die Pause". "Beide [Kunst und Liebe] ändern unser Zeitgefühl”.

10 "Lyrik lädt uns ein zu der einfachsten und schwierigsten aller Begegnungen, der Begegnung mit uns selbst”. 
me na passagem publicada pela própria Domin (2005b, p. 21), no texto "Unter Akrobaten und Vögeln - fast ein Lebenslauf (Entre acrobatas e pássaros - quase um currículo) ${ }^{11 "}$ :

Eu, H.D., sou extremamente jovem. Vim ao mundo somente em 1951. Chorando, como todos chegam a esse mundo. Não era na Alemanha, embora o alemão seja minha língua materna. Se falava espanhol, e o jardim diante de casa estava repleto de coqueiros. Mais exatamente, onze palmeiras. Todos machos, portanto, sem frutos. Meus pais estavam mortos quando eu vim ao mundo. Minha mãe havia morrido poucas semanas antes. ${ }^{12}$

O início do texto já demonstra a encenação: H.D., ou seja, Hilde Domin, nasce poeticamente em 1951, porém apenas após o retorno a Alemanha é assim nomeada. O pseudônimo fora uma sugestão de Wolfgang Weyrauch. Esse episódio aparece no poema "Landen dürfen" (DOMIN, 2009, p. 238), incluído em Gesammelte Gedichte, de 1987:

Nomeie-se, me disse
Quando pisei na Europa,
Com o nome da sua ilha. ${ }^{13}$

Outro dado digno de menção diz respeito à data de nascimento real de Hilde Löwenstein. Como afirmado antes, fora no ano de 1909, do que se percebe um nascimento poético tardio, aos 42 anos. No ano de publicação de seu primeiro livro, Nur eine Rose als Stütze (Apenas uma rosa como apoio), a poeta já teria 50 anos. Como era uma idade muito

${ }^{11}$ Primeiramente, em 1964, em Besondere Kennzeichnen, organizado por Karl Ude. Munique: Piper, 1964. Depois, inserido em Von der Natur nicht vorgesehen. Munique: Piper, 1974

12 "Ich, H.D., bin erstaunlich jung. Ich kam erst 1951 auf die Welt. Weinend, wie jeder in diese Welt kommt. Es war nicht in Deutschland, obwohl Deutsch meine Muttersprache ist. Es wurde spanisch gesprochen, und der Garten vor dem Haus stand voller Kokospalmen. Genauer, es waren elf Palmen. Alles männliche Palmen und also ohne Früchte. Meine Eltern waren tot, als ich auf die Welt kam. Meine Mutter war wenige Wochen zuvor gestorben”.

13 "Nennen Sie sich, sagte einer/ als ich in Europa an Land ging,/ mit dem Namen Ihrer Insel." 
avançada para uma debutante, decidiu-se alterar um pouco o ano de nascimento, que passou a ser 1912, conforme consta nas primeiras edições de seus livros. Anos depois, por razões que ainda não me são claras, passou-se a usar o ano correto, de 1909.

Domin já possuía um vasto conhecimento poético como leitora e também pelas aspirações artísticas de seu marido Erwin, e não se pode atribuir esse nascimento de 1951 como um estouro de inspiração. $O$ ato de sua consciência artística se mostra quando ela, após escrever o primeiro poema, o traduz para o espanhol, "sem nenhuma outra intenção, senão ver se o texto se sustentava" ${ }^{14}$ (DOMIN, 2005b, p. 176). A escrita poética, emergida de uma situação extrema, após a notícia do nascimento da mãe e no momento em que vivia afastada do marido, envolvido com viagens e com uma amante, foi um modo de permanecer na vida - "enquanto eu escrevia, continuava viva" 15 (ibidem, p. 177). Essa formulação, aqui citada do texto "Ich schreibe, weil ich schreibe" (Escrevo, porque escrevo), de 1971, reaparece em "Leben als Sprachodyssee" (Vida como odisseia linguística), de 1979 (ibidem, p. 39):

Quando cheguei ao limite, após a morte da minha mãe, sobre a qual não direi nada aqui, eu tinha então a língua à qual eu tinha servido por tantos anos. Sabia o que era uma palavra. Me libertei através da língua. Se não tivesse me libertado, não estaria mais viva. Escrevi poemas. Escrevi em alemão, naturalmente. Logo que os poemas surgiram, os traduzi ao espanhol, para ver como eles se sustentavam enquanto texto. Para tomar distância. Naquela época, publicar não estava em questão. Escrever era salvação. Eu tinha 39 anos $^{16}$, quando minha vida, como por si mesma, se tornou uma pré-história para a segunda vida, que a desde então eu conduzo. ${ }^{17}$

14 "Ohne andere Absicht, als um es auszuprobieren, um zu sehen, ob der Text standhielte".

15 "Solange ich schriebt, lebte ich".

16 Como mencionado anteriormente, Domin falseava a data de nascimento, passando de 1909 para 1912. Em 1951, portanto, a poeta tinha 42, e não 39. Esse dado não é mera curiosidade, mas demonstração de aspectos ficcionais incluído no autobiográfico.

17 "Als ich nach dem Tode meiner Mutter, über den ich hier nichts sage, an eine Grenze kam, da hatte ich plötzlich die Sprache, der ich so lange gedient hatte. Ich 
Ao voltar a Alemanha, em 1954, as publicações entrarão no horizonte da poeta, primeiro em revistas e, em 1959, com o volume Nur eine Rose als Stütze (Apenas uma Rosa como apoio). Um pouco antes, em 1958, seria publicada a antologia Rose aus Asche - spanische und spanischamerikanische Lyrik seit 1900 (Rosa das cinzas - poesia espanhola e hispano-americana desde 1900), organizada e traduzida por Erwin Palm. À medida que iam se estabelecendo na Alemanha, Domin se tornava cada vez menos a secretaria de Erwin, e se erguia como uma das importantes vozes da poesia do pós-guerra. A "odisseia linguística” e o percurso quase épico de suas vidas contribuíam para um interesse crescente em relação à figura de Hilde Domin.

\section{Percurso: ao arquivo}

É somente pelo trabalho em arquivo que poderá ser adicionado mais um dado à problematização do nascimento poético de Domin: os primeiros poemas não datam de 1951, mas de 1949, conforme constata Nikola Herweg (DOMIN, 2009, s. 31) na edição organizada por ela juntamente com Melanie Reinhold, em que se inclui, além dos poemas publicados em vida, uma seleção de inéditos. Esses aspectos, que redimensionam o campo autobiográfico, não devem servir como provas detetivescas para aquilo que confere ou não confere entre vida e obra, mas sim apontam a fluida fronteira entre o real e o ficcional. Em outras palavras: entre o mundo da vida (Lebenswelt) e o mundo ficcional (Kunstwelt). Não se trata de estabelecer dois polos e conferir a cada um deles uma abertura e um ponto de conexão que levaria de um a outro. Estão sobrepostos e nem sempre é possível reconhecer - ou reconhecer facilmente - em qual deles nos encontramos. Não é possível estabelecer uma clara diferenciação entre Hilde Palm e Hilde Domin, em que uma pudesse ser encontrada nas ruas, nos mercados, etc, e a outra residisse apenas nos textos.

wußte, was ein Wort ist. Ich befreite mich durch Sprache. Hätte ich mich nicht befreit, ich lebte nicht mehr. Ich schreibe Gedichte. Ich schrieb deutsch, natürlich. Kaum waren die Gedichte entstanden, so übersetzte ich sie ins Spanische, um zu sehen, was sie als Texte aushielten. Um Abstand zu bekommen. Veröffentlichen war damals keine Frage. Schreiben war Rettung. Ich war 39 Jahre alt, als mein Leben, wie von selbst, zur Vorgeschichte wurde für das zweite Leben, das ich seither führe". 
Outros dois aspectos em relação ao trabalho no arquivo são de interesse no presente artigo: o de Domin - e Erwin - como uma espécie de agente literária de poetas espanhóis e a questão, já abordada anteriormente, sobre a língua como salvação.

Em "'Spanische Poesie' = 'Romantische Poesie'? August Wilhelm Schlegel als Literaturvermittler in Spanien und Deutschland" (Poesia espanhola = poesia romântica? August Wilhelm Schlegel como transmissor literário na Espanha e na Alemanha), Raphaela Braun (2016) demonstra o trabalho de duas vias de Schlegel como divulgador tanto da poesia espanhola em território de língua alemã como das ideias do romantismo alemão em território espanhol. Mais de cem anos depois, Hilde Domin e Erwin Palm exercerão um papel semelhante, não mais com o romantismo, logicamente, contribuindo para o trânsito entre as poesias alemã e espanhola. Na afirmação de Maria Eugenia Boaventura (2009, p. 13), comentando o distante caso de Mário Faustino, no Brasil, "a história intelectual de um escritor, ou mesmo de uma geração, deve muito à interferência de pessoas isoladas que, por deleite próprio, se rodeiam de um belo arsenal de livros, discos, filmes, etc., tornando-se o centro de referência e de atração de valores jovens". Decerto, existem diferenças entre os casos de Schlegel, Domin e Faustino, e o que cabe aqui não é explorá-los, mas perceber como determinados movimentos podem influir na apreensão de culturas alheias e, por conseguinte, na transformação da cultura própria.

Além da já referida antologia organizada e traduzida por Erwin Palm, Rose aus Asche (Rosa das cinzas), outras contribuições, diretas e indiretas, foram feitas pelo casal, abrindo campo para poetas como Vicente Aleixandre e Luis Cernuda. Devido ao fato de o espólio de Erwin ainda não estar catalogado, concentro-me somente nas correspondências de Hilde Domin.

Em carta de 26 de setembro de 1957, enviada desde Munique, Domin comenta com Cernuda o pedido que fizera a Suhrkamp, para incluí-lo entre autores da casa. Um pedido dessa ordem não é algo menor, se se considera que a Suhrkamp é uma das maiores casas editorais da Alemanha e que uma publicação por eles oferece uma enorme visibilidade ao autor. Em 26 de x de 1958 (mês desconhecido), sugere a ele a leitura de Lord Chandos, de Hugo von Hofmannsthal, acrescentando o seguinte comentário: “(...) trata de la unidad y de la otredad del mundo. Y de la unión, imprevista, que de momento se presenta, pero que con la voluntad no podría provocarse, del yo con los objetos. Que, en esse determinado 
período de su vida (la carta está escrita en 1902), eran a menudo objetos ínfimos". Inclui, ainda, um trecho - segundo ela, mal traduzido:

Entre las matérias juxtapuestas no existe ni uma que no podría entrar en mí. Como si me cuerpo estaria hecho todo de cifras que me abren todo. $\mathrm{O}$ como si podríamos entrar en una nueva, misteriosa relación com toda la existencia, si empezáramos a pensar con el corazón.

Que autores de diferentes países se correspondam e intercambiem sugestões de obras, etc., não é um fato inédito. $\mathrm{O}$ que temos, aqui, no entanto, é a possibilidade, enquanto estudiosos de literatura, de acompanhar certo circuito não visível, espécie de micropartículas observáveis apenas pelo microscópio.

Em carta de 26 de setembro de 1957, ou seja, mesma data da mencionada carta a Cernuda, Domin escreve a Vicente Aleixandre, comentando haver falado com um subdiretor da Suhrkamp sobre as publicações do poeta espanhol. Quase dois anos depois, em carta de 31 de maio de 1959, comunica a ele a leitura da tradução publicada na Alemanha, fazendo, porém, ressalvas ao trabalho da tradutora, cujo nome não é mencionado na $\operatorname{carta}^{18}$ : "En vários sítios, quizá su lenguaje sea algo más sencillo del que la traductora se atreve a emplear. Hay que ser poeta para permitirse el lujo de tanta sencillez". Domin, em ambos os casos, demonstra um perfil generoso, cuja preocupação e cuidado com a obra alheia não parece ter interesses mercadológicos imediatos. Não é demais lembrar que até então Domin não era uma poeta publicada em livro, o que viria acontecer no mesmo 1959.

Por outro lado, se percebe uma enorme vontade de fazer parte dos círculos de poetas e de ser lida por eles. Em carta a José Ramón Sender, de 31 de março de 1963, escreve: "No sé si sabe que soy poeta, que publique [sic] dos tomos de poesias. Todo lo que podría decirse sobre esto, lo halla en las hojas anexas, una de las cuales está en inglês. (Las reseñas, incluídas también, desde luego en alemán). Es decir que tengo lectores en serio, aúnque, desde luego, en los Estados Unidos haya aún poca gente que me conozca”. Quase três anos antes, em carta de 12 de abril de 1960 ao mesmo destinatário, informa como estava tentando

18 Por carta de Vicente Aleixandre a Domin, no final de 1958, deduz-se que a tradutora seja Erika Lorenz. 
incluir a obra dele no ambiente literário alemão. Para superar a barreira da língua, traduz poemas próprios ao espanhol, e, aproveitando-se de um comentário satisfatório de Vicente Aleixandre, tenta seduzir o editor Rudolf Hirsch, da S. Fischer, a publicar seus poemas:

Eu traduzi [o poema] apenas para lê-lo a Vicente Aleixandre, por causa de seu famoso cedro, que tinha sido o primeiro impulso. Alexandre me olhou um pouco surpreso, pois até então eu era apenas a esposa do organizador de Rose aus Asche, pegou o papel da minha mão e leu ele próprio, dizendo: "é profundo, é intenso, é poético”. O senhor não quer publicá-lo? ${ }^{19}$

Essa carta de 16 de setembro de 1956 abre ainda mais espaço para uma relação - iniciada em 1955 - que se intensificará ao longo dos anos e levará Domin a mais uma crise extrema, próxima daquela vivida em 1951, na República Dominicana. Antes de entrar nessa questão, que retoma o aspecto da língua como salvação, desenvolvo um pouco mais essa postura de Domin como promotora da própria obra.

No seu espólio, no Arquivo Literário Alemão, encontram-se inúmeras cartas de Domin a praticamente todos os autores de renome de sua época, como Günter Eich, Paul Celan, Ingeborg Bachmann, bem como a críticos - Marcel Reich-Ranicki - e filósofos - Hans-Georg Gadamer. O então chanceler da Alemanha Ocidental, Konrad Adenauer, por exemplo, recebeu um exemplar de Nur eine Rose als Stütze (Apenas uma rosa como apoio), em 1960, e até Charles Chaplin se encontra entre os destinatários de Domin. Em carta de 27 de outubro de 1979, o renomado crítico e teórico René Wellek escreve - em alemão - a Domin, lamentando não ser possível a realização de uma palestra dela, em New Haven, nos Estados Unidos, devido a algumas ocupações.

A atuação de Domin não se restringia somente à promoção de sua obra e à divulgação de autores espanhóis na Alemanha. Suas atividades se

19 "Ich übertrug es [das Gedicht] eigentlich nur um es Vicente Aleixandre vorzulesen, wegen seines berühmten Zedernbaums, der den ersten Antoss gegeben hatte. Aleixandre sah mich etwas erstaunt an, nachdem er mich bis dato nur als die Frau des Herausgebers von 'Rose aus Asche' kannte (...) nahm mir das Blat taus der Hand, las es selbst und sagte: 'es profundo, es intenso, es poético'. Wollen Sie es nicht veröffentlichen?"” 
estendiam ao debate político e a reflexões sobre o fazer poético, principalmente numa época de reconstrução e restabelecimento - ou estabelecimento, se se prefere - de uma Alemanha recém recuperada da Segunda Guerra. Em 1968, publica Wozu Lyrik heute (Por que a poesia hoje), em que expõe sua obra crítica e teórica, sempre muito próximas de reflexões sobre o lugar e a função sociais da poesia. Dois anos antes havia organizado e publicado o volume Doppelinterpretationen - das zeitgenössische Deutsche Gedicht zwischen Autor und Leser (Duplas interpretações - o poema alemão contemporâneo entre autor e leitor), em que 31 poetas são convidados a interpretar um poema próprio, que será também interpretado por um crítico - daí o "dupla", no título. No inverno de 1987/88, oferece o ciclo de palestras da Frankfurter Poetik-Dozentur, em que aborda os problemas da poesia de pós-guerra, a questão dos perseguidos políticos e das mulheres, a prática de leitura e a condição do escritor exilado. Este ciclo de palestras foi publicado sob o título Das Gedicht als Augenblick von Freiheit ( $\mathrm{O}$ poema como momento de liberdade), em 1993. De 1998 é a antologia Nachkrieg und Unfrieden (Pós-guerra e inquietude), organizada juntamente com Clemens Greve. Nesse volume, inclui poemas de 1945-1995, de 75 poetas, entre eles, Bertolt Brecht, Paul Celan, Erich Fried e até mesmo Durs Grünbein, na época um jovem poeta - seu aclamado Schädelbasislektion (Lição da base craniana) é de 1991 - e hoje uma das referências da poesia alemã. Um vasto material sobre o trabalho em cima desses livros, incluindo cartas trocadas com os poetas e críticos da antologia, pode ser consultado no espólio da poeta.

Um dos materiais mais extensos no espólio de Hilde Domin é, sem dúvida, sua correspondência com o editor Rudolf Hirsch, que, assim como as cartas trocadas com seu marido, Erwin Palm, redimensiona a aparência da grande história de amor em exílio e recondiciona a leitura do "tu" de muitos poemas, bem como o entendimento do único romance escrito por ela, Das zweite Paradies (O segundo paraíso). Publicado em 1968, o livro fora recusado na casa editorial que publicava Domin e na qual Hirsch trabalhava, S. Fischer, e acabou sendo publicado pela editora Piper, de Munique. O motivo não poderia ser mais simples - e digno de melodramas: um dos personagens retratados no romance era justamente Hirsch, como parte de uma relação fracassada (HERWEG, 2011, p. 144). Se a história de amor é fracassada, tampouco é diferente a recepção da obra. H.L. Arnold intitula assim sua resenha: "Fehlschlag in Sachen Liebe. Hilde Domin scheitert als Roman-Autorin" (Insucesso em questão 
de amor. Hilde Domin fracassa como romancista; apud HERWEG, 2011, p. 145). O que críticos não sabem - e o que provavelmente podemos, hoje, apontar como um dos motivos do fracasso do romance - é que alguns trechos do livro são passagens literais das cartas (ibidem, p. 145). Novamente saindo da esfera meramente anedótica e situando o problema nos estudos literários, percebe-se o constante problema da relação entre mundo real e mundo ficcional. Esse conflito, presente e banal para qualquer romancista ${ }^{20}$, parece ter sido descuidado por Domin, que, enquanto poeta, no entanto, sempre soube manipular o acontecimento, conferindo-lhe uma força que independesse da validade real dele, mesmo que depois quisesse fazer o leitor retornar ao acontecimento, através da publicação de escritos autobiográficos, de suas palestras, entrevistas.

Se "a forma interior de uma obra de arte se assemelha a um segundo cosmo, a uma segunda natureza" (SANTIAGO, 2003, p. 18), então o que o arquivo nos proporciona é um trabalho semelhante ao do físico, que ultrapassa o nível de percepção humana e observa fenômenos aos quais jamais poderíamos ter acesso sem o uso de instrumentos. Além do mais, proporciona um trabalho de antropologia literária que se desdobra em uma antropologia da literatura ${ }^{21}$, na tentativa de entender as motivações existentes na escrita de formas - as poéticas, por exemplo -

${ }^{20}$ Esse é um problema também vivido por historiadores, uma vez que trabalham com narrativas. Hayden White abordou esse problema em Meta-história - a imaginação histórica do século XIX. trad. José Laurênio de Melo. São Paulo: EdUSP, 2008, e em La ficción de la narrativa - ensayos sobre historia, literatura y teoria - 1957 . 2007. trad. María Julia De Ruschi. Buenos Aires: Eterna Cadencia, 2011. Um breve debate sobre a abordagem de White se encontra em um diálogo entre Aleida Assmann e Krzysztof Pomian, em que o historiador franco-polonês contraria o que ele considera duas correntes equivocadas, a que "pretende reduzir a história à recordação" e a que pretende "reduzir história à retórica" (ASSMANN, 2011, p. 156). White se encontraria na segunda. Assmann, porém, discorda de Pomian, afirmando que a "historiografia, de muito claro, tem (ao menos) três dimensões: a científica, a memorial e a retórica" (ibidem, p. 156) e que elas não se excluem. O risco estaria na absolutizar qualquer uma delas.

${ }^{21}$ As três perguntas basilares da relação entre antropologia e literatura são 1) Por que os seres humanos produzem literatura?; 2) O que é dito sobre o homem, na literatura?; e 3) Como se relacionam as representações literárias com as outras articulações linguísticas ou com outras formas mediais de sua representação? A primeira questão é abordada na antropologia da literatura, as demais, pela antropologia literária. 
que concorrem com outras formas de expressão. Como visto anteriormente, a escrita foi salvação para Domin, num momento em que o peso do mundo parecia insuportável. Também agora, na relação com Hirsch, ela retornará a uma situação extrema. Em carta de 7 de julho de 1959, ela escreve ao editor:

Chorando, lhe escrevo. Como eu, sabe lá Deus, fiz tantas vezes. O senhor não me deixa nada. Absolutamente nada! Agora o senhor ainda me aniquila como autora, como se eu tivesse recém começado. Se posso escrever, isso é o único que ainda me mantém viva ${ }^{22}$.

Quase oito anos depois, é ainda a escrita que servirá como único apoio em momentos de extrema fragilidade. Talvez Walter Jens (1982, p. 60) não esteja errado ao afirmar, na resenha a Nur eine Rose als Stütze (Apenas uma rosa como apoio) que essa "rosa" seria a língua alemã. Desse modo, é possível voltar aos poemas e ler, em "Wer es könnte" (Quem poderia), de Hier (Aqui; 2009, p. 127), publicado em 1964, o "wer" (quem) como a língua, e não como um pronome que possa ser ocupado por uma pessoa.

$$
\begin{aligned}
& \text { Quem poderia } \\
& \text { lançar o mundo } \\
& \text { para o alto } \\
& \text { com que o vento } \\
& \text { passe adiante }{ }^{23} \text {. }
\end{aligned}
$$

Aqui, ressalto como alguns elementos do trabalho em arquivo podem contribuir para o trabalho hermenêutico. Não é demais dizer que não se trata de afirmar categoricamente que o "wer" (quem) do poema é a língua alemã, o que residiria numa arbitrariedade sem nenhum ganho para o estudo da literatura. Muito mais se trata de procurar as complexas correlações presentes numa obra literária. Karl Eibl (1996, p. 7) chega a

\footnotetext{
22 "Ich schreibe Ihnen weinend. Wie ich es, Weiss Gott, oft getan habe. Sie lassen mir nichts. Gernichts! Nun richten Sie mich noch als Autor zugrunde, ehe ich nur beginne. Wenn ich schreiben kann, so ist es das Einzige, was mich noch am Leben hält".

23 "Wer es könnte/ die Welt/ hochwerfen/ daß der Wind/ hindurchfährt."
} 
afirmar que "apenas através das correlações se pode responder à pergunta: por que justamente aqui e agora? ${ }^{24 ”}$. Ou seja: perguntar sobre condições possíveis para a emergência daquela forma, o que nos leva a um segundo nível de pergunta, aquele sobre nós mesmos: quais as condições possíveis para a nossa leitura aqui e agora, uma vez que não faz sentido o reconhecimento de uma leitura universal ${ }^{25}$ ?

Para a constituição do mundo ficcional, Domin refaz o seu aqui e agora, finge $e^{26}$ seu mundo, que para o leitor ficará no intervalo entre mundo ficcional e mundo da vida, ficará entre a dúvida do que é e do que pode ser. A relação com Rudolf Hirsch não permanece submersa apenas por um problema moral. A história de amor no exílio, do casal que viveu a experiência da odisseia linguística e que, mais de vinte anos depois, retornou à terra natal, precisava - ou queria -ser mantida. Marion Tauschwitz (2012, p. 12), secretária e biógrafa de Domin, afirma que a poeta retrabalhou inúmeras vezes seus poemas, antes da publicação, inclusive alterando datas e inserindo um novo contexto biográfico, "para que a linda imagem de um harmônico diálogo de vida com seu marido Erwin Palm não tivesse seu brilho ofuscado no tempo de vida dele e dela"27.

A consciência da finitude em contraponto a uma possível infinitude da escrita transparece mesmo nos momentos de maior perturbação mental. No dia 16 de abril de 1959, portanto menos de dois

\footnotetext{
24 "Nur über Korrelationen ist die Frage zu beantworten: Weshalb gerade hier und jetzt?"

${ }^{25}$ Muitos séculos antes, Blaise Pascal (apud GLEISER, p. 83) se colocava um problema antropológico semelhante: "Quando considero a curta duração da minha vida, engolida pela eternidade que passou e passará antes e após o pequeno intervalo que preencho, ou que possa ver, engolfado pela imensidão infinita de espaços que me são inescrutáveis e que não me conhecem, tenho medo, e me surpreendo de estar aqui e não acolá, agora e não antes ou depois. Quem me pôs aqui? Quem deu a ordem e direção para que este espaço e este intervalo de tempo sejam ocupados por mim?”.

${ }^{26}$ Para um debate sobre o "fingir" da literatura, cf. ISER, Wolfgang. Fingieren als anthropologische Dimension der Literatur. Konstanz: Universitätsverlag, 1990. Não remeto, aqui, ao problema da "poética do fingimento", topos da poesia portuguesa desde Fernando Pessoa. Se é possível uma aproximação entre uma literatura e outra, apenas um cuidadoso trabalho é capaz de indicar.

27 “(...) damit der schöne Schein eines harmonischen Lebensgespräches mit ihrem Mann Erwin Palm zu seinen und ihren Lebzeiten nicht getrübt wird”.
} 
meses antes da carta citada acima, Domin escreve um bilhete para Hirsch: "Se ainda me ama de verdade, o senhor pode abrir e ler essa carta" e "estou nos limites das minhas forças. Sério". O envelope, não entregue a ele, contém a seguinte informação: "ao senhor Dr. Rudolf Hirsch, após a minha morte. Caso ele morra antes de mim, queimar, sem abrir, essa carta" ${ }^{28}$. A finitude à qual me refiro é, logicamente, a da vida enquanto algo biológico. A vida (bio) escrita (grafia) se ficcionaliza também no ambiente que consideraríamos como real.

Somente um binarismo simplório poderia isolar aquilo que é real do que é ficcional na relação entre Domin e Hirsch. Se considerarmos as cartas como algo real, então o problema fica acomodado, ainda que sem uma resposta mais precisa. Quem embarca na história - epistolar - de amor com Hirsch é Hilde Palm ou Domin já seria uma personagem para si mesma? Esse problema se abre a uma série de questões que não poderiam ser tratadas aqui, incluindo as perguntas pelo limite - ou limites - de uma consciência do real e do ficcional, bem como em embates sobre sujeito a partir da psicologia, da fenomenologia e, também, na antropologia filosófica ${ }^{29}$.

28 "Sie können diesen Brief nur aufmachen und lesen, wenn Sie mich in Wahrheit noch lieb haben". "Ich bin am Rande meiner Kräfte. Im Ernst"."Herrn Dr. Rudolf Hirsch nach meinem Tode. Falls er vor mir gestorben sein sollte, ist dieser Brief ungeöffnet zu verbrennen".

${ }^{29}$ Para o problema do sujeito entre psicologia e fenomenologia, cf. ALMEIDA, Rogério Miranda de e LETENSKI, Irineu. "Husserl: a crise das ciências e o esquecimento do Lebenswelt". In: Dissertatio 42. PUC-PR, 2015 https://periodicos.ufpel.edu.br/ojs2/index.php/dissertatio/article/view/8467.

Almeida (p. 70) retoma o problema da objetivação do sujeito, na psicologia: "Ela [a psicologia] o [sujeito] compreende como outro qualquer objeto que se prestaria a uma investigação sem levar em conta a característica essencialmente experiencial, vital, subjetiva, deste mesmo objeto. Ora, o que Husserl lamente é justamente o fato de que, desde a instauração do objetivismo moderno do conhecimento do mundo, aquilo que se chama de psicologia adquiriu o status de uma ciência objetiva do subjetivo". Em relação à antropologia filosófica, encontrase o problema do homem e sua excentricidade, tema abordado por Max Scheler em A posição do homem no cosmos. trad. Marco Antônio Casanova. Rio de Janeiro: Forense Universitária, 2003. pp. 44-45. “(...) o homem como ser espiritual é o ser que se coloca acima de si mesmo como ser vivo e acima do mundo. Enquanto tal, ele também é capaz da ironia e do humor que constantemente envolvem uma elevação por sobre a própria existência". A questão da excentricidade do homem também será tratada por Helmut Plessner. Gesammelte Schriften. Frankfurt am 


\section{Percurso: à literatura}

As contribuições do trabalho no espólio de Hilde Domin podem transcender os estudos literários, uma vez que podem oferecer respostas a historiadores que se ocupem com a Segunda Guerra e o pós-guerra, a filósofos ou até mesmo àqueles que se dediquem a uma interpretação psicológica de cartas e diários. $\mathrm{O}$ que esse trabalho em arquivo pode trazer para os estudos literários é sempre uma questão de posicionamento, embora eu insista que também para as pesquisas que procurem isolar a forma literária de todas essas atribuições exteriores - e por que não dizer, anteriores - a ela, o arquivo abre um campo de reflexões possíveis sobre a formação dessa forma, quando o pesquisador pode, muitas vezes, captar reflexões sobre o processo de elaboração do texto literário, deixadas pelo autor em cartas e diários, ou ter acesso a manuscritos e poder acompanhar algumas alterações feitas até a publicação. Que nem todas as modificações sejam relevantes é uma avaliação que só pode ser feita posteriormente.

O proposto, aqui, se abre em duas vertentes que não se excluem: uma, pela via da antropologia literária, tentando entender a visão de ser humano que emerja da obra literária bem como tentando uma aproximação com o ser humano que deu forma a essa obra; outra, através daquilo que parta da proposta do próprio autor, no caso, Domin. Essa autobiografia poética se insere num mundo mais amplo, em que encontramos os textos teóricos, políticos, as palestras, entrevistas, a própria ficcionalização da autobiografia poética, como no texto em que a poeta narra seu segundo nascimento.

A pesquisa colaborativa é outra marca dos estudos de literatura que se utilizem de arquivo. No caso de espólios já catalogados, o pesquisador possui a vantagem de acessar um material previamente organizado, embora deva estar atento que esse caminho desenhado pode induzir a repostas que, numa catalogação diferente, seriam outras. O primeiro indício disso é a própria seleção do que interessa ou não ao arquivo, uma tarefa institucional, baseada numa série de critérios que escapam ao controle do pesquisador que encontra o material já disposto. Além do material escrito (cartas, diários, esboços, contratos, etc.), o

Main: Suhrkamp, 2015. Para as diferenças entre Schler e Plessner, cf. FISCHER, Joachim. Philosophische Anthropologie. Eine Denkrichtung des 20. Jahrhunderts. Freiburg: Alber, 2008 
espólio de Domin possui objetos, como fotos isoladas, álbuns de família e pequenos pertences que o grupo de arquivistas responsável por receber o espólio, logo após a morte da poeta, em 2006, selecionou, descartando materiais que consideraram sem importância.

Quanto maior conhecimento dos textos literários o pesquisador tiver, mais rica será sua pesquisa em arquivo, pois poderá mais rapidamente associar passagens encontradas em cartas, por exemplo, com ideias que reconhece em poemas, contos, etc.

Para além das fronteiras nacionais, o trabalho em arquivo possibilita a chance de um olhar mais amplo, uma vez que autores de determinada nação se correspondem com autores de tantos outros lugares. $O$ próprio aspecto linguístico não permanece restrito, pois materiais nos mais variados idiomas podem ser encontrados no arquivo. $\mathrm{O}$ que o arquivo de Domin pode dizer sobre os tantos lugares pelos quais ela passou? O que o arquivo de Stefan Zweig, também disponível no Deutsches Literaturarchiv, pode dizer sobre o Brasil? Um projeto que visa a essa rede supranacional vem sendo desenvolvido e pode ser consultado em http://www.global-archives.de/. A imagem na página de apresentação do site é, curiosamente, um trecho de uma carta de Stefan Zweig a Berthold Viertel, escrita em Petrópolis, em 28 de outubro de 1941.

Um rico material aguarda pesquisadores que se debrucem sobre o pós-guerra e queiram entender fenômenos mais baixos, aqueles vividos pelo chamado homem comum. Se isso ultrapassa os limites dos estudos literários, não quer dizer que se excluam. Existe uma relação entre história - ou História - e estética? Qual evento e qual grandeza provocam uma mudança estética? Houve mudança estética nos poetas de exílio? (ENGLMANN, 2001). Se uma leitura imanentista pode perceber a alteração das formas poéticas, o entendimento dessas alterações na relação - ou não - com os eventos históricos exige um desdobramento de métodos.

Essas e outras questões ficam abertas para futuros trabalhos e debates, seja através de artigos, livros, seja nos encontros em simpósios e congressos. $\mathrm{O}$ diálogo não se encerra.

\section{BIBLIOGRAFIA}

ALMEIDA, Rogério Miranda de e LETENSKI, Irineu. "Husserl: a crise das ciências e o esquecimento do Lebenswelt". In: Dissertatio 42. PUCPR, 
https://periodicos.ufpel.edu.br/ojs2/index.php/dissertatio/article/vi ew/8467

ASSMANN, Jan. Das kulturelle Gedächtinis - Schrift, Erinnerung und politische Identität in frühen Hochkulturen. München: C.H. Beck, 2013

BOAVENTURA, Maria Eugenia. "Um militante da poesia". In:

FAUSTINO, Mário. O homem e sua hora - e outros poemas. São Paulo: Companhia das Letras, 2009

BRAUN, Raphaela. "'Spanische Poesie' = 'Romantische Poesie'? August Wilhelm Schlegel als Literaturvermittler in Spanien und Deutschland”. In: STROBEL, Joachen. August Wilhelm Schlegel im Dialog - Epistolatirät und Interkulturalität. Paderborn: Ferdinand Schöningh, 2016

DOMIN, Hilde und GREVE, Clemens. Nachkrieg und Unfrieden Gedichte als Index 1945-1995. Frankfurt am Main: S. Fischer, 1998

DOMIN, Hilde. Wozu Lyrik heute - Dichtung und Leser in der gesteuerten Gesellschaft. Frankfurt am Main: S. Fischer, 2005a - Gesammelte Autobiographische Schriften - fast ein Lebenslauf. Frankfurt am Main: S. Fischer, 2005b . Das zweite Paradies. Frankfurt am Main: S. Fischer, 2006; München: Piper, 1968

. Sämtliche Gedichte. Hrsg. Nikola Herweg und Melanie Reinhold. Frankfurt am Main: S. Fischer, 2009a . Die Liebe im Exil - Briefe an Erwin Walter Palm aus den Jahren 1931-1959. Hrsg. Jan Bürger und Frank Druffner. Frankfurt am Main: S. Fischer, 2009b - Das Gedicht als Augenblick von Freiheit - Frankfurter PoetikVorlesungen. Frankfurt am Main: S. Fischer, 2009c

EIBL, Karl. "Literaturgeschichte, Ideengeschichte, Gesellschaftsgeschichte - und 'das Warum der Entwicklung”. In: IASL 21, 2. Heft. Org. Georg Jäger et ali. Berlin: De Gruyter, 1996

ENGLMANN, Bettina Poetik des exils - Die Modernität der deutschsprachigen Exilliteratur. Berlin: De Gruyter, 2001

FISCHER, Joachim. Philosophische Anthropologie. Eine Denkrichtung des 20. Jahrhunderts. Freiburg: Alber, 2008

GLEISER, Marcelo. A Ilha do Conhecimento - os limites da ciência e a busca por sentido. Rio de Janeiro: Record, 2014 
GUMBRECHT, Hans Ulrich. Produção de presença - o que o sentido não consegue transmitir. trad. Ana Isabel Soares. Rio de Janeiro: Contraponto, PUC-Rio, 2010

ISER, Wolfgang. Fingieren als anthropologische Dimension der Literatur. Konstanz: Universitätsverlag, 1990

HERWEG, Nikola. nur ein land/ mein sprachland - Heimat erschreiben bei Elisabeth Augustin, Hilde Domin und Anna Maria Jokl. Würzburg: Königshausen \& Neumann, 2011

JENS, Walter. "Vollkommenheit im Einfachen". In: Heimkehr ins Wort Materialien zu Hilde Domin. Org. Bettina v. Wangenheim. Frankfurt am Main: S. Fischer, 1982

KOSELLECK, Reinhart. Futuro passado - contribuição à semântica dos tempos históricos. trad. Wilma Patrícia Maas e Carlos Almeida Pereira. Rio de Janeiro: Contraponto, PUC-Rio, 2006

PLESSNER, Helmut. Gesammelte Schriften. Frankfurt am Main: Suhrkamp, 2015

SANTIAGO, Silviano. "Com quantos Paus se Faz uma Canoa". In: SOUZA, Eneida Maria de e MIRANDA, Wander Melo (org.). Arquivos Literários. São Paulo: Ateliê, 2003

SCHELER, Max. A posição do homem no cosmos. trad. Marco Antônio Casanova. Rio de Janeiro: Forense Universitária, 2003

TAUSCHWITZ, Marion. Hilde Domin - das heikle Leben meiner Worte. Mainz: André Thiele, 2012

VOGEL, Harald e GANS, Rose Ausländer - Hilde Domin Gedichtinterpretationen. Baltmannsweiler: Schneider Verlag, 1998

WHITE, Hayden. Meta-história - a imaginação histórica do século XIX. trad. José Laurênio de Melo. São Paulo: EdUSP, 2008

. La ficción de la narrativa - ensayos sobre historia, literatura y teoria 1957-2007. trad. María Julia De Ruschi. Buenos Aires: Eterna Cadencia, 2011

Recebido em: 13 de outubro de 2016.

Aceito em: 10 de dezembro de 2016. 